DOI: https://dx.doi.org/10.33289//JRPC.11.1.2021.11(15)

\title{
RECENT TRENDS AND ADVANCES USED \\ IN THE PARKINSON'S DISEASE
}

\author{
Keerthi Neelufor* and D. Rispa \\ Department of Pharmacy Practice \\ Hindu College of Pharmacy, Guntur, Andhra Pradesh, India.
}

\begin{abstract}
BRIEF SUMMARY OF PARKINSON'S DISEASE
Parkinson's disease

The other names of this disease are "Primary parkinsonism, paralysis agitans, idiopathic parkinsonism, shaking palsy" and in ayurveda it is referred to as Kampavata as Kampa means tremor in Sanskrit.
\end{abstract}

\section{Definition}

The Parkinson's disease is a long term progressive type of neurodegenerative disorder of the central nervous system that mainly affects the motor system

The Epidemiology of the parkinson's disease is among 1,00,000 population about 4.5 to 21 cases are estimated per year

- Nearly 1 million will be living with parkinson's disease in US by 2020

- In India there is a crude type of prevalence rate of 14.1 rate in 1,00,000 among the kashmir population in North India

- It is increasing by the advance age present in $1 \%$ of the people with age over 65 years

- Early onset PD will be starting at age range of 40 years and it is of 3 to $5 \%$ cases and juvenile occurring before age 21 years and young onset of age 21-40 years

- More than 10 million worldwide are living with PD

- Men are 1.5 times more likely to have Parkinson's disease than women.

\section{Etiology}

There are genetical and environmental types of causes but mostly cause will be loss of dopaminergic neurons of substantia pars nigra, presence of lewy bodies , autoimmune factors etc.,

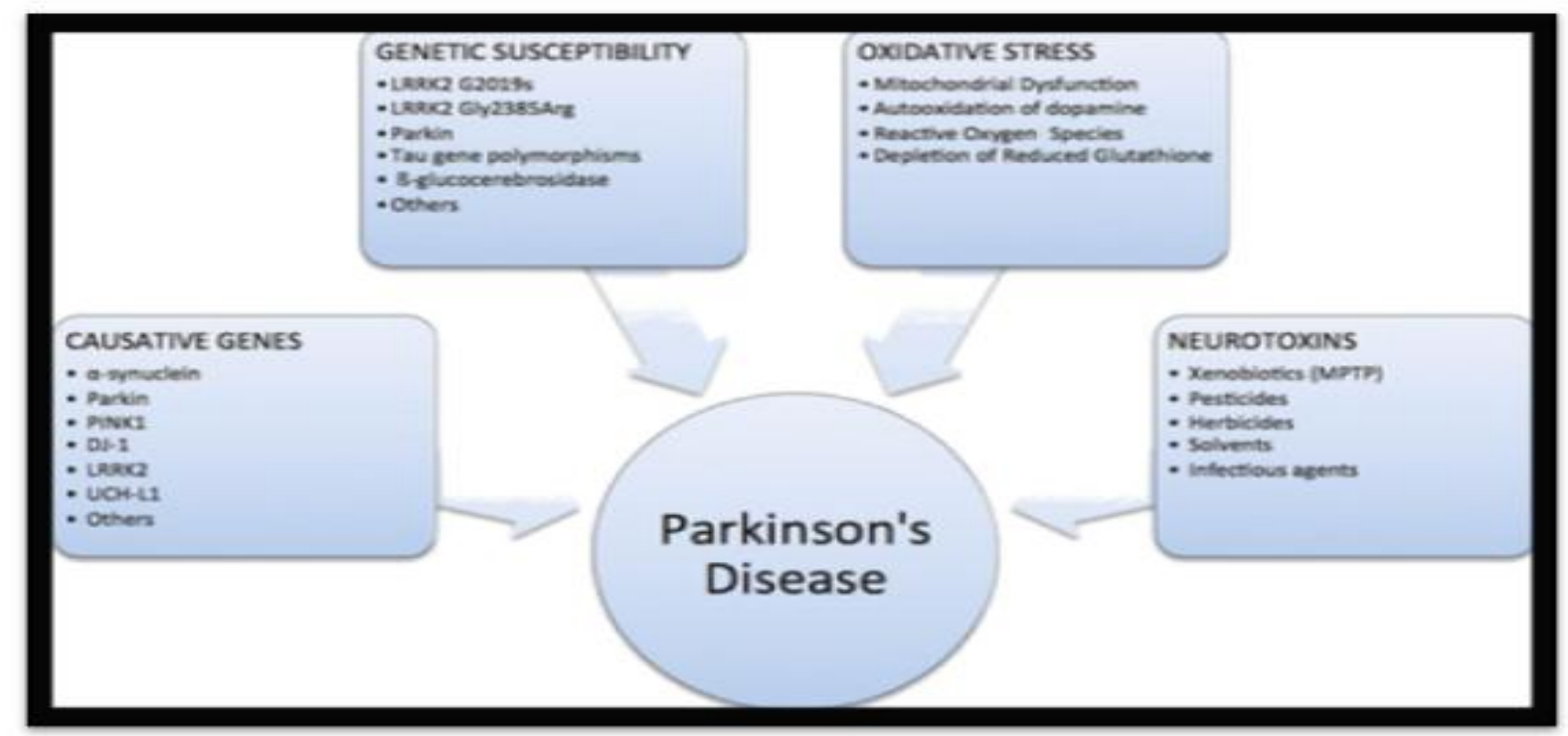



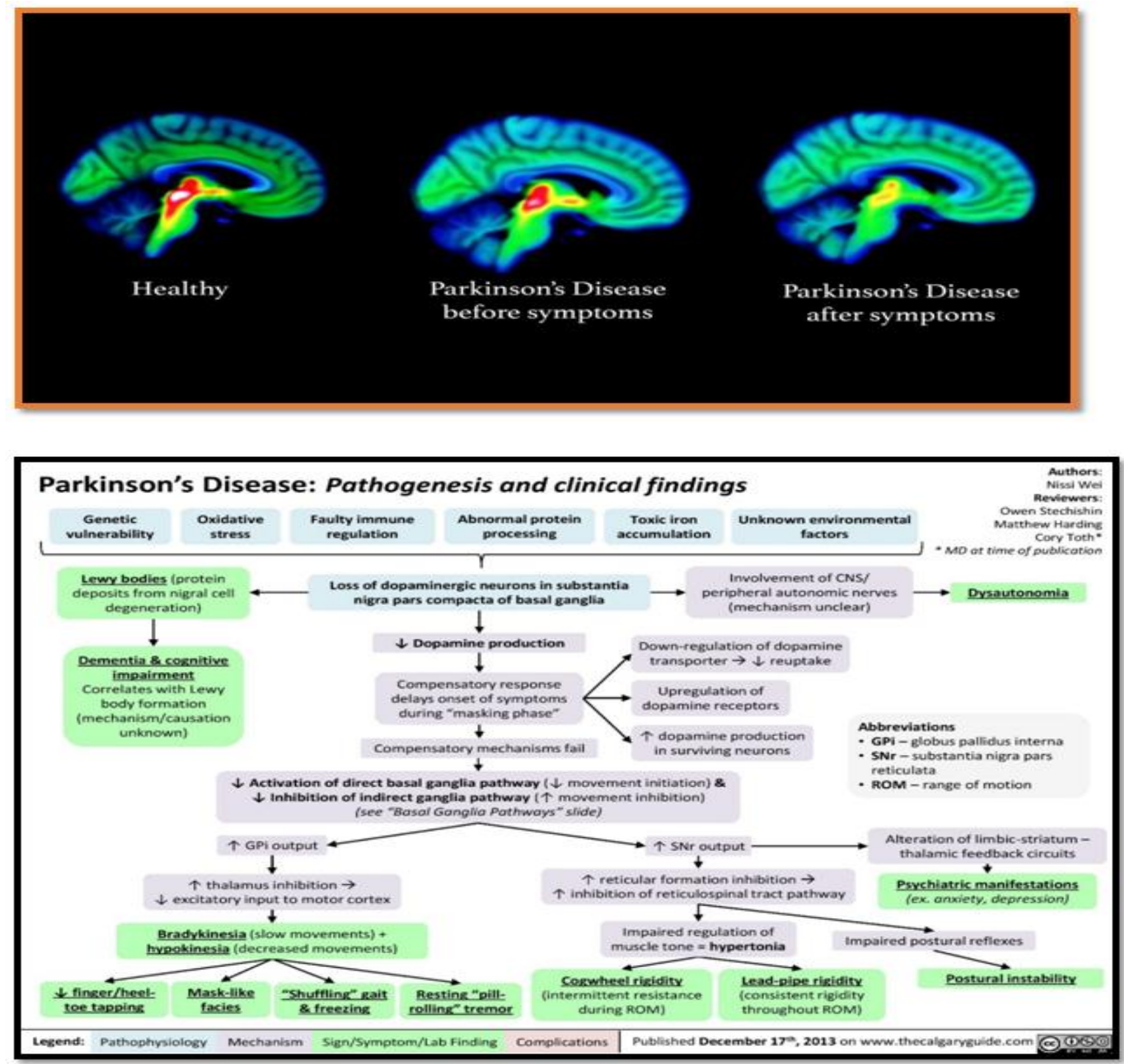

\section{STAGES OF PARKINSON'S}

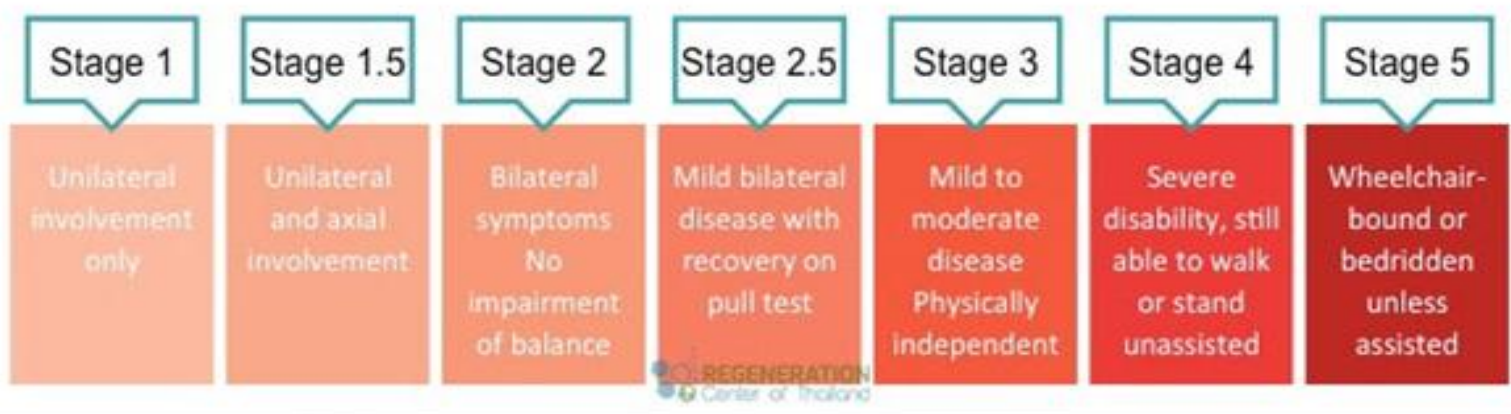

Risk factors for parkinson's disease 
The risk factors for parkinson's disease are

1. Age

2. Sex

3. Heredity

4. Exposure to chemicals and toxic metals like herbicides, fungicides, agent orange, mercury, bismuth , lead, aluminium , iron , copper etc.,

5. History of head trauma and smoking

6. Drugs or medication like synthetic heroin etc.,

The Diagnosis is based upon the view of signs and symptoms, medical history, physical examination , neurologic examination, blood and other lab tests, MRI, PET scan, ultrasound of brain and in most cases a SPECTscan i.e., single photon emission computerized tomography scan called as dopamine transporter scan [ Dat scan ] is done but mostly the physical examination, neurological examination and signs and symptoms will tell the proper diagnosis rather if the scans are suggested

\section{TREATMENTS USED IN PARKINSON'S DISEASE}

The goals of PD treatment are to minimize symptoms, disability and side effects while maintaining the quality of life

Education of patients and caregivers, exercise and proper nutrition are essential

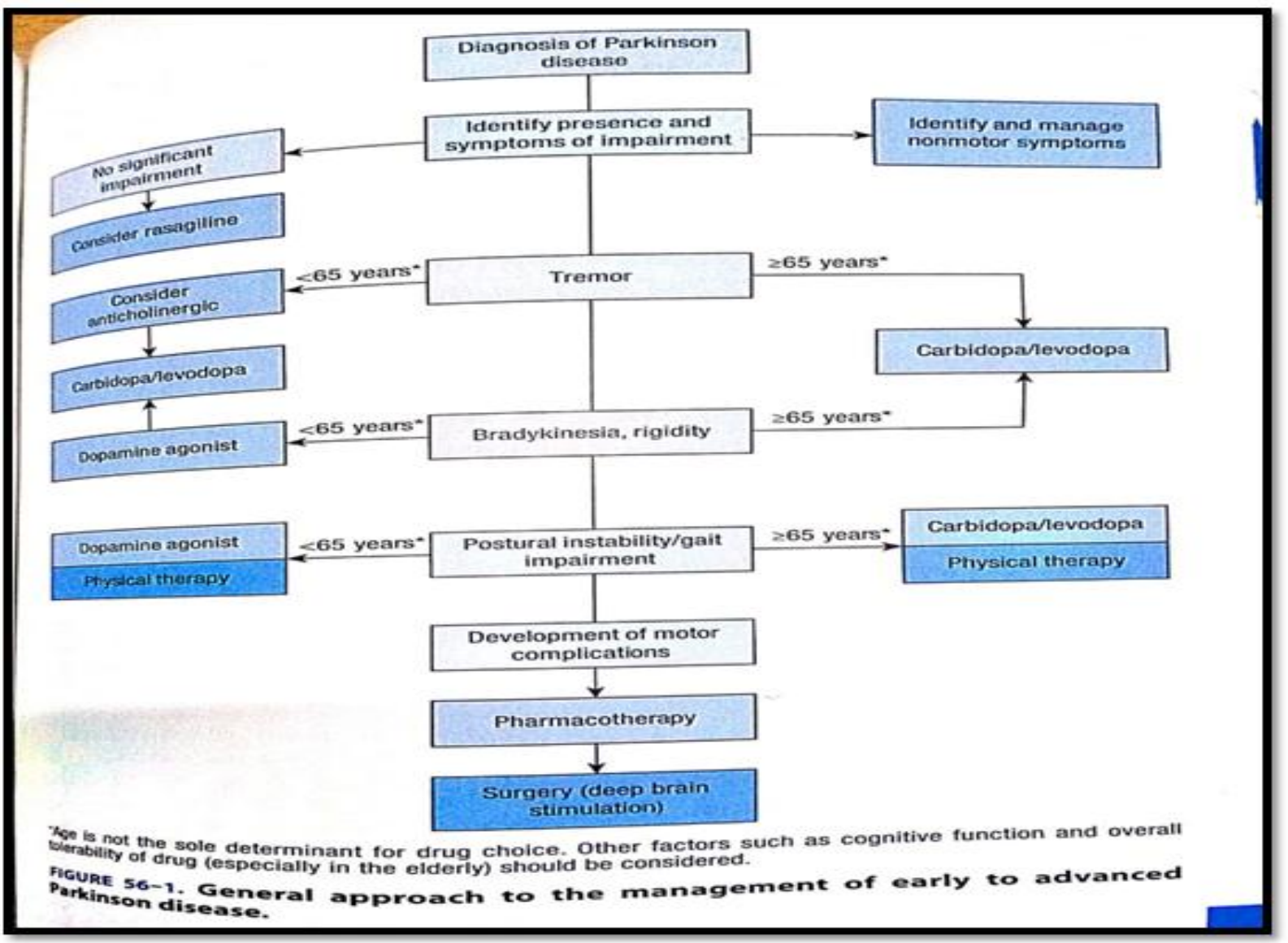

The above diagram is the algorithm for management of early to advanced PD and their doses are given below at Fig no 2

> Anticholinergic drugs can improve tremor and sometimes dystonic [ involuntary muscle movements ] features, improve bradykinesia or other disabilities and patients with pre existing cognitive deficits and elders are at a greater risk for central anti cholinergic side effects

> Amantadine provides most benefits for tremor,rigidity,bradykinesia and mostly used for LDopa induced dyskinesia and it's doses should be reduced in renal dysfunction patients with creatinine clearances and for haemodialysis patients i.e., $[100 \mathrm{mg} / \mathrm{day}$ with creatinine clearance of $30-50 \mathrm{ml} / \mathrm{min}(0.50-0.84 \mathrm{ml} / \mathrm{s}), 100 \mathrm{mg}$ every other day for 
creatinine clearances of $15-29 \mathrm{ml} / \mathrm{min}(0.25-0.49 \mathrm{ml} / \mathrm{s})$ and $200 \mathrm{mg}$ every 7 days for creatinine clearance less than $15 \mathrm{ml} / \mathrm{min}(0.25 \mathrm{ml} / \mathrm{s})$ ] and Livedoreticularis [a diffuse mottling of skin in upper or lower extremities ] is a common but reversible side effect

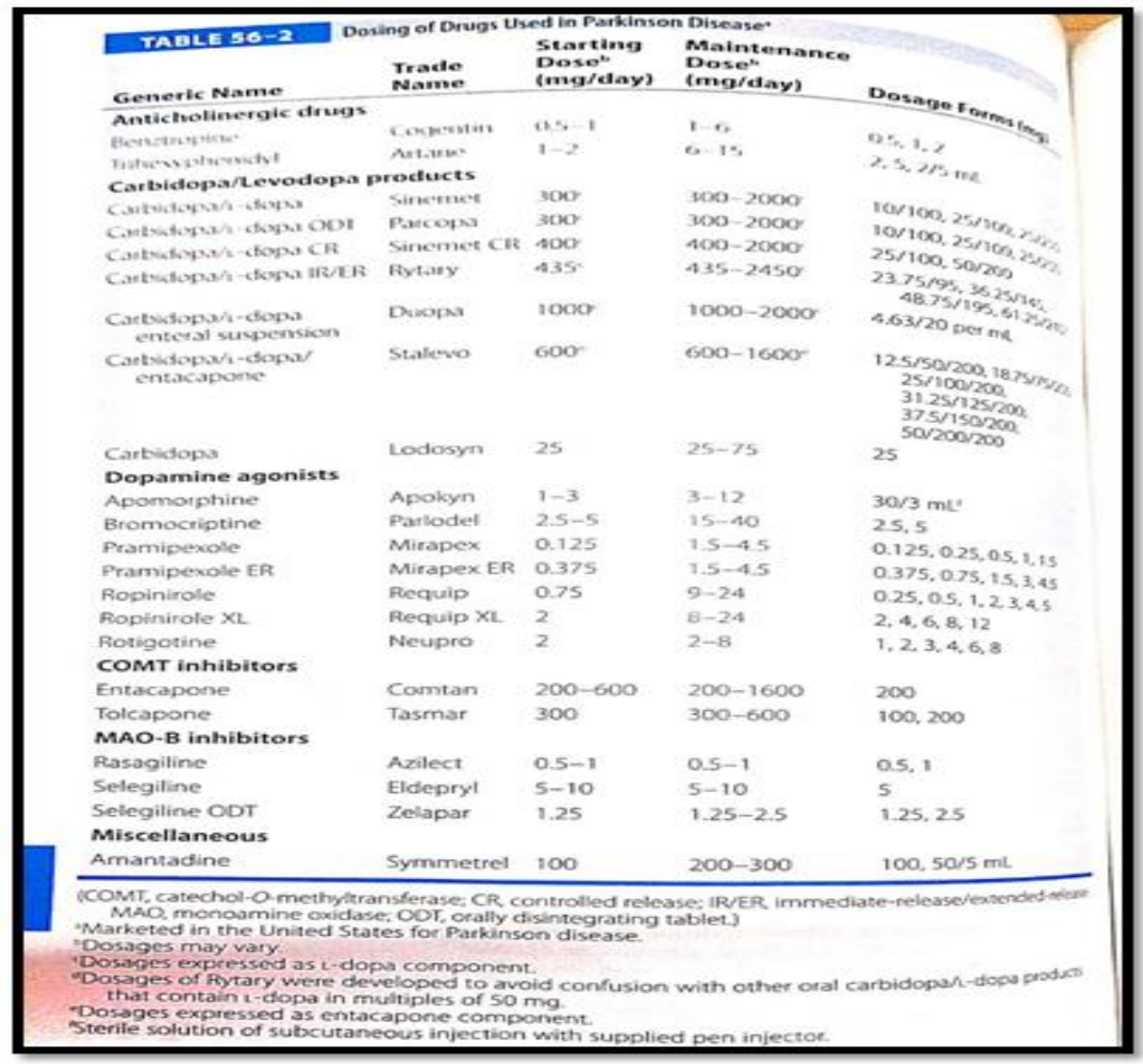

Levodopa or L-Dopa with carbidopa combination and in CNS and peripherally this L-Dopa is converted by L-amino acid decarboxylase [ L-AAD] to dopamine

$>$ In periphery the carbidopa or benserazide can block L-AAD thus increasing CNS penetration of administered L-Dopa and decreasingdopamine adverse effects like nausea, cardiacarrhythmias,postural hypotension and vivid dreams and elimination $1 / 2$ life of levodopa is about 1 hour and adding of carbidopa or benserazide can extend $1 / 2$ life of 1.5 hours and adding of COMT inhibitor can extend it to 2 to 2.5 hours.

There are some responses like

1. End of dose wearing off is related to increasing loss of neuronal dopamine storage capability and short $1 / 2$ life of L-Dopa

2. Delayed on or no on can result from delayed gastric emptying or decreased absorption in duodenum

3. Dyskinesias- involuntary choreiform movements usually involving neck, trunk and extremities

4. Freezing - Episodic inhibition of lower extremity motor function

5. Off period dystonia - Muscle contractions most commonly in distal lower extremities like feet or toes occurs often in early morning 
TABLE 56-4 Common Motor Complications and Possible Initial Treatments

\section{Effect}

End-of-dose "wearing off" (motor fluctuation)

-Delayed on" or "no on" response

Start hesitation ("freezing")

Peak-dose dyskinesia Possible Treatments

Increase frequency of carbidopa/1-dopa doses; add either
COMT inhibitor or MAO-B inhibitor or dopamine ag add or switch to extended release carbidopa agonis: (ie, Rytary)

Give carbidopa/t-dopa on empty stomach; use cart L-dopa ODT; avoid carbidopa/t-dopa SR; use carbidopa/ subcutaneous

Increase carbidopa/t-dopa dose; add a dopamine agonist or MAO-B inhibitor; utilize physical therapy along with assistive walking devices or sensory cues (eg, rhythmic commands, stepping over objects)

Provide smaller doses of carbidopa/L-dopa; reduce dose of adjunctive dopamine agonist; add amantadine

(COMT, catechol-O-methyltransferase; $M A O$, monoamine oxidase; ODT, orally disintegrating tablet
SR, sustained release)

> MAO-B inhibitors i.e., Monoamine oxidase Binhiblike selegiline blocks dopamine breakdown and can extend on time of L-Dopa up to 1 hour and it often permits reduction of LDopa dose by as much as 1 half and combining MAO-B inhib with meperidine\& opioid analgesics is contraindicated because of a small risk of serotonin syndrome

$>$ COMT inhib i.e., Catechol-O-Methyltransferase inhibitors are used in conjunction with carbidopa / levodopa to prevent peripheral conversion of L-Dopa to dopamine and tolcapone use - limited potential for fatal liver toxicity and monitor LFT's and brownish orange urine colouration occur and entacapone has shorter $1 / 2$ life

$>$ The dopamine agonists like ergot derivatives - bromocriptine and non ergots likepramipexole,rotigotine and ropinirole are beneficial adjuncts in patients experiencing fluctuation in response to L-Dopa and they decrease frequency of off periods and provide an L-Dopa sparing effect and one of the drug like apomorphine iscontraindicated with serotonin 3 receptor blockers like ondansetron

The below figures are the side effects of the drugs and some of the non motor symptoms and their possible treatments

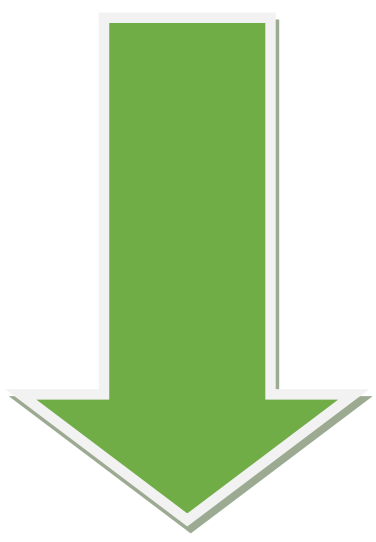




\begin{tabular}{|c|c|c|c|}
\hline Generic Name & Adverse Drug Reaction & Monitoring Parameter & Comments \\
\hline \multirow[t]{2}{*}{ Amutadine } & Confusion. & Mental status; renal function & Reduce dosage, adjust dose for rensl imparmeen \\
\hline & Whedo reticulatis & $\begin{array}{l}\text { Lower extremity examination; anble } \\
\text { edems }\end{array}$ & Reversible upon drug discontinuation \\
\hline Ganuropine & $\begin{array}{l}\text { Anticholinergic effects, confusion } \\
\text { drowsiness }\end{array}$ & $\begin{array}{l}\text { Dry mouth, mental status, constipation, } \\
\text { uninary terention, vision }\end{array}$ & $\begin{array}{l}\text { Reduce dosage, avoid in edderly and in those with a history of } \\
\text { constipation, memory impaiment, urinary retention }\end{array}$ \\
\hline Trhexypnenidy & See benztropine & See benzropine & See benztropine \\
\hline Carbidopa/l-dopa & $\begin{array}{l}\text { Drowsiness } \\
\text { Dyskinesias } \\
\text { Nausea }\end{array}$ & $\begin{array}{l}\text { Mental starus } \\
\text { Abnormal involuntary moventents } \\
\text { Nausea }\end{array}$ & $\begin{array}{l}\text { Reduce dose } \\
\text { Reduce dose, add amantadine } \\
\text { Take with food }\end{array}$ \\
\hline \multicolumn{4}{|l|}{ Cout inhiocors } \\
\hline Entacapone & $\begin{array}{l}\text { Augmentation of } \mathrm{L} \text {-dopa side effects; } \\
\text { also diarthea }\end{array}$ & $\begin{array}{l}\text { See carbidopa/i-dopa; also bowel } \\
\text { movements }\end{array}$ & Reduce dose of $t$-dopa; antidiarheal agents \\
\hline Tolcapone & See entacapone; also liver towicity & See carbidopa/-dopa; also ALT/AST & $\begin{array}{l}\text { See carbidopa/-dopa; also at start of therapy and for every dose } \\
\text { increase, ALT and AST levels at baseline and every } 2-4 \text { weeks } \\
\text { for the first } 6 \text { months of therapy; atterward monitor based on } \\
\text { clinical judgment. }\end{array}$ \\
\hline \multicolumn{4}{|l|}{ Dopamine Agonists } \\
\hline Apomorphine & $\begin{array}{l}\text { Drowsiness } \\
\text { Naused } \\
\text { Orthostatic hypotension }\end{array}$ & $\begin{array}{l}\text { Mental status } \\
\text { Nausea } \\
\text { Blood pressure, diziness upon standing }\end{array}$ & $\begin{array}{l}\text { Reduce dose } \\
\text { Premedicate with trimethobenzamide } \\
\text { Reduce dose }\end{array}$ \\
\hline Bromocriptine & $\begin{array}{l}\text { See pramiperole; also pulmonary } \\
\text { fibrosis }\end{array}$ & Mental status; also chest radiograph & Reduce dose; chest radiograph at baseline and once yearly \\
\hline
\end{tabular}

\begin{tabular}{|c|c|c|c|}
\hline TABLE 56-3 & nitoring of Potential Adverse Reactions to $D$ & ug Therapy for Parkinson Disease (Continued) & \\
\hline Generic Name & Adverse Drug Reaction & Monitoring Parameter & Comments \\
\hline Pramipexole & $\begin{array}{l}\text { Confusion } \\
\text { Drowsiness } \\
\text { Edema } \\
\text { Hallucinations/delusions } \\
\text { Impulsivity } \\
\text { Nausea } \\
\text { Orthostatic hypotension }\end{array}$ & $\begin{array}{l}\text { Mental status } \\
\text { Mental status } \\
\text { Lower extremity swelling } \\
\text { Behavior, mental status } \\
\text { Behavior } \\
\text { Nausea } \\
\text { Blood pressure, dizziness upon standing }\end{array}$ & $\begin{array}{l}\text { Reduce dose } \\
\text { Reduce dose } \\
\text { Reduce dose or discontinue medication } \\
\text { Reduce dose or discontinue medication } \\
\text { Discontinue medication } \\
\text { Titrate dose upward slowly; take with food } \\
\text { Reduce dose }\end{array}$ \\
\hline Ropinirole & See pramipexole & See pramipexole & See pramipexole \\
\hline Rotigotine & $\begin{array}{l}\text { See pramipexole; also skin irritation } \\
\text { at site of patch application }\end{array}$ & See pramipexole; also skin examination & See pramipexole; rotate patch application site \\
\hline MAO-B Inhibitors & & & \\
\hline Rasagline & Nausea & Nausea & Take with food \\
\hline Selegiline & $\begin{array}{l}\text { Agitation/confusion } \\
\text { Insomnia } \\
\text { Hallucinations } \\
\text { Orthostatic hypotension }\end{array}$ & $\begin{array}{l}\text { Mental status } \\
\text { Sleep } \\
\text { Behavior, mental status } \\
\text { Blood pressure, dizziness upon standing }\end{array}$ & $\begin{array}{l}\text { Reduce dose } \\
\text { Administer dose earlier in day } \\
\text { Reduce dose } \\
\text { Reduce dose }\end{array}$ \\
\hline
\end{tabular}




\section{TABLE 56-1 Nonmotor Symptoms and Possible Treatments}

\section{Symptom}

Anxiety

Cognitive impairment

Constipation

Daytime sleepiness

Depression

Drooling

Dysphagia

Fatigue

Falling

Hallucinations/psychosis

Impulse control disorder

Insomnia

Orthostatic hypotension

\section{Overactive bladder}

Pain

Pain

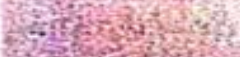

REV sleep behavior disorder Restless legs syndrome

\section{Possible Treatments}

Cognitive behavioral therapy, seleeteresereto

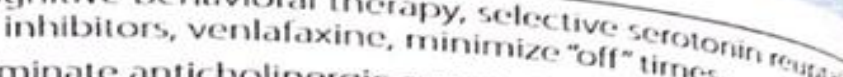

Eliminate anticholinergic agents Adt tirnes. inhibitor.

Fiber, hydration, excrcise, laxat

Proper night time sleep hygienes, stool softeners agonist, referral to sleep specialist to dose of donare sleep disorders.

Selective serotonin reuptake inhibitor, newer-generation
serotonin norepinephrine reuptake inhibitor, cogniti behavioral therapy

Local injection of botulinum toxin, atropine sublingua drop, glycopyrrolate, ipratropium sublingual spray

Referral to speech therapist, dysphagia diet, avoid an. cholinergic medications, manage dry mouth.

Caffeine, armodafinil, modafinil, proper night time sleep hygiene, referral to sleep specialist to rule out sleep disorder.

Referral to physical therapy; assistance with ambulation minimize risk for bone fractures, treat osteoporosis

Eliminate adjunctive medications, especially anticholinergc agents and dopamine agonists. Add clozapine, quetiapine pimavanserin.

Discontinue dopamine agonist or add clozapine, quetiapine or naltrexone

Nonbenzodiazepine $\mathrm{GABA}_{\mathrm{A}}$ agonists, trazodone.

Reduce dose of alpha-blockers, dopamine agonist, diureic vasodilators. Abdominal compression, add salt and water to diet, water boluses, fludrocortisone, midodine droxidopa, pyridostigmine.

Behavioral therapies (eg, bladder training, fluid managemert pelvic floor muscle exercises), antimuscarinic agents. pelvic floor muscle exercises), antions of botulinum tovin. mirabegron, intradetrusor injections of bain (eg, dystonic.

Treatment as per type of pain (eg, minimize "off" times. musculoskeletal, neuropathic), minimize of therapy. appropriate referral to orthopedics, physical therap. pain specialist, rheumatology.

Clonazepam, melatonin.

Dopamine agonist at bedtime: gabapentin.

(GABA, $Y$-aminobutyric acid; REM, rapid eye movement.)

Educate the patients and caregivers about recording medication doses \& administration times and duration of on \& off periods

Monitor symptoms, side effects and activities of daily living and individualize therapy and other medications that may worsen motor symptoms,memory,falls or behavioural symptoms should be discontinued if possible

\section{NEW/RECENT TRENDS/ADVANCES INTRODUCED TO THIS DISEASE}

The recent type of trends that which are introduced in PD are like

- In August 2019, FDA has approved a drug i.e., Istradefylline of Nourianz brand for parkinson's off time when the symptoms return between medication doses

- This Istradefylline belongs to adenosine A2A antagonists which work by blocking adenosine chemical and boosts the dopamine i.e., brain chemical that decreases in PD and this Istradefylline is OD type of drug that can be added to a medication regimen consisting of levodopa/ carbidopa to decrease "off time." Common side effects may include dyskinesia (abnormal, involuntary movement), dizziness, constipation and other symptoms like insomnia, hallucinations etc., 
The other recently approved type of drugs are

1. INBRIJA [Levodopa oral inhalation powder ] - 21/12/2018 approved by FDA\& it is indicated for the intermittent treatment of off episodes in patients with Parkinson's disease treated with carbidopa/levodopa and it is contraindicated with thepatients currently taking a nonselectiveMAOinhibitor or who have recently (within 2 weeks)taken a nonselective MAO inhibitor and it's mechanism of action will be as a the metabolic precursor of dopamine, crosses the blood-brain barrier and after it is converted to dopamine in the brain.

2. Xadago [ Safinamide ] is another drug from Newron Pharmaceuticals approved byFDA [ US Food and drug administration ]\& it is a MAO-B type of inhibitor \& indicated for adjunctive treatment to levodopa/carbidopa in patients with PDexperiencing "off" episodesand it's dose is $50 \mathrm{mg}$ OD oral and it can be increased upto $100 \mathrm{mg}$ and it's particular mechanism is not known but as it is a MAO-B inhibitor it inhibits MAO-B activity byblocking the catabolism of dopamine, as a result to increase in dopamine levels andsubsequent increase in dopaminergic activity in the brain. It is contraindicated with other MAO inhibitors,opioiddrugs, dextromethomorphan and a history of hypersensitivity etc.,

3. In 2019 the CDER [ Center for drug evaluation and research - Division of FDA ] has approved a drug i.e., FluorodopaF 18injection, a radioactive diagnostic agentfor use in positron emission tomography [PET] studies to help diagnoseadult patients with suspected Parkinsonian syndromes, a group of disorders, that includes Parkinson's diseasethat may occur when there is a reduction in the ability ofdopamine, an essential chemical in the body that works inthe brain, to function normally.

The other kinds of treatments that are recently and in few years are like use of electrical neuromodulation in Parkinson's disease and techniques of electrical neuromodulation are" Deep brain stimulation, transcranial direct current stimulation, transcranial alternating current stimulation, direct cortical stimulation.

DEEP BRAIN STIMULATION remains the most common and effective form of electrical stimulation for the treatment of PD.

- It is one of the most prevalent type of neurosurgical procedure for PD providing effective relief for some motor \& non motor symptoms

- It is a good type of technique and it's successful chances are also good but it's limitation is invasive

- DBS involves the surgical implantation of electrodes that stimulate subcortical structures including the subthalamic nucleus and globuspallidusinternus

- It offers significant improvements in motor symptoms and fluctuations in comparison to best medical therapy in some advanced PD patients

- Exact mechanism of action of DBS is not known and now it is believed as DBS efficacy is rooted in a reversible information lesionthat disrupts the expression of pathological neural activityacross the motor circuit.

TRANSCRANIAL DIRECT CURRENT STIMULATION is non-invasive treatment \& is a new type of treatment option for PD and neurological diseases

- It is easy to handle, low cost and fewer side effects and good changes or adherence is seen in the patients by this treatment

- The evidence suggests that transcranial direct current stimulation (tDCS) is a good evidence for clinical practice\&most likely impacts on motor symptoms of the disease, withmost prominent results relating to rehabilitation

- It's use is applied in supplemental motor areas together with a gait training can facilitate motor learning and modulate neurons for better potentiation of exercises together with patients with walking difficulties due to PD

- Utility is limited due to its weak effects and high variability, with medication state.

DIRECT CORTICAL STIMULATION of the motor cortex in the treatment of PD has been trialled with varying success over the years

- Stimulation can be subdural, but minimally invasive epidural methods seem to be preferred due to reduced surgical risks

- Efficacy has been variable, but is generally considered less efficacious than DBS

- This is potentially due to the dependency between stimulation site (cortical or sub-cortical) and behavioural effects, and confounded by limits on stimulation intensity in order to prevent seizure onset. 
- Stimulation efficacy could be improved by determining the optimum stimulation site according to patient specific brain connectivity in order to reveal the "sweet spot" for modulating downstream nuclei in the motor circuit.

TRANSCRANIAL ALTERNATING CURRENT STIMULATION application in parkinson's symptomology has remained experimental and these treatments will be including electrodes producing the electric impulses and all these treatments provide actions like neurotransmitter concentration changes and both Tcs types \& DBS will have complete field shaping by possible developments in hardware

- In this electrical neuromodulation techniques to achieve a effective neuromodulation- All forms have been associated with neuroplastic effects and pharmacological dependencies, and an emerging recognition that underlying brain state is an important and some times these factors may overlap also

- The Pharmacological impact of stimulation, either by director indirect methods, will affect the efficacy of subsequentperiods of stimulation.

The below diagram is "PUTATIVE DISEASE MODIFYING THERAPIES FOR PD"

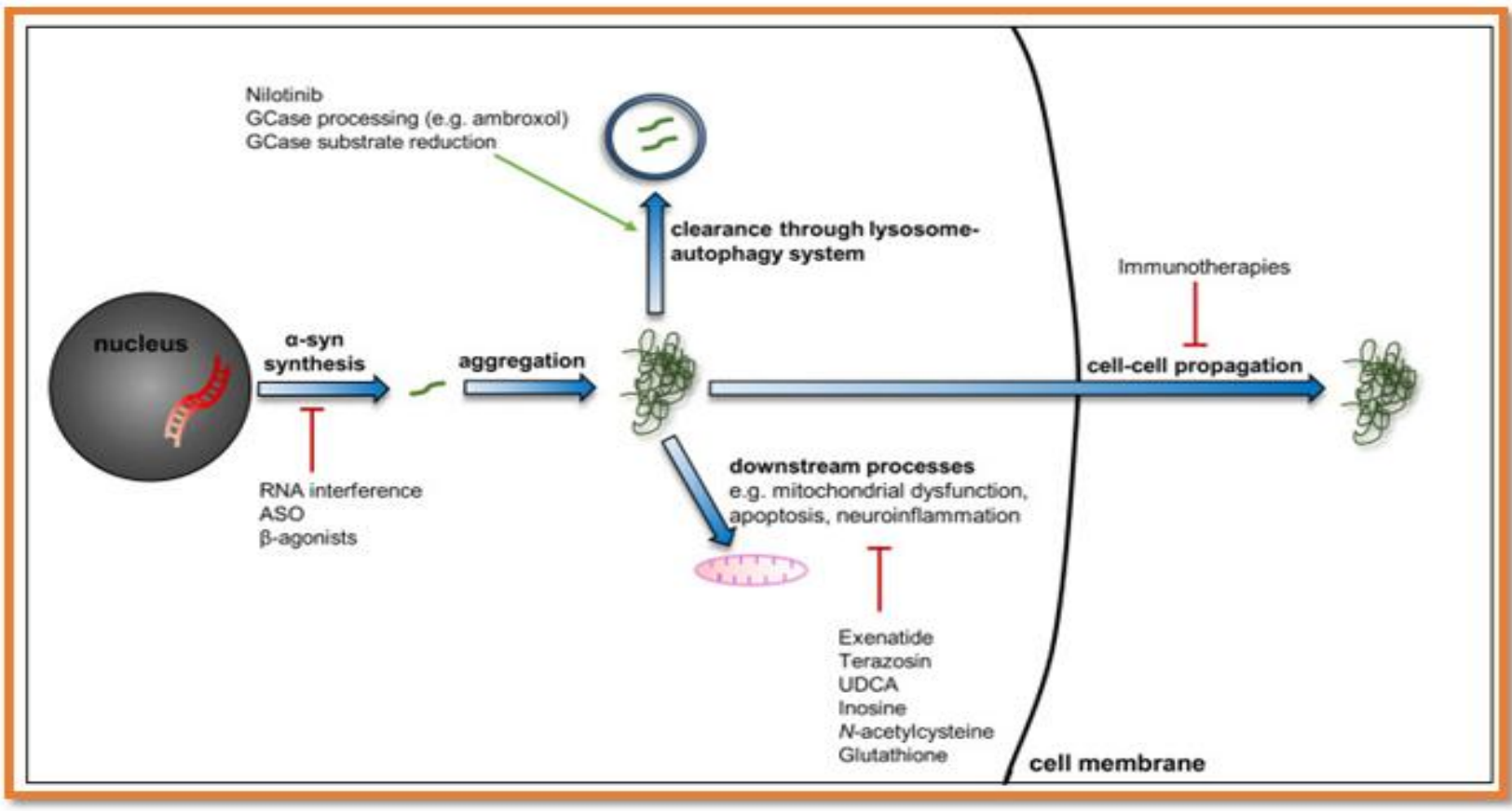

The other kind of treatments that are involved and are in clinical trials stage or going on are

- Immunotherapies

A humanised monoclonal antibody prasinezumab or PRX002, Prothena brand has been shown to reduce free serum alpha synuclein at approximaately 97 percent and cleared phase 1 clinical trials and trial 2 is under way and other antibody or drugs like BIIB054 [Biogen] target $n$ terminal portion of alpha synuclein and it's $1^{\text {st }}$ trial is good and it is undergoing $2^{\text {nd }}$ trial and other approaches like antisense oligonucleotide and rnainterference techniques to reduce its synthesis but they remained in the pre clinical studies.

- Drug repurposing

It is a technique in which use of drugs through which the reduction of alphasynucleinpathology or having anybeneficial effects other processesare implicated in Parkinson's disease. The following tablewill be giving the information regarding the most promising agents that are being consideredfor Parkinson's disease treatment or the putative or commonly accepted disease modifying therapies for Parkinson's disease table is given below 


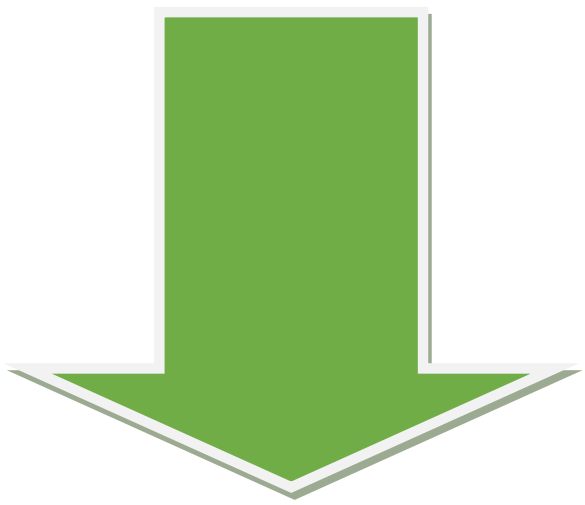

Clinical trials of putative disease-modifying treatments for Parkinson's disease.

\begin{tabular}{|c|c|}
\hline Drug/class & Proposed mechanism \\
\hline \multicolumn{2}{|c|}{ a-synuclein reduction } \\
\hline$\beta$-agonists & $\begin{array}{l}\text { Reduced a-synuclein transcription through acetylation of } \\
\text { promoters and enhancers of the SNCA gene } \underline{28}\end{array}$ \\
\hline Nilotinib & $\begin{array}{l}\text { Inhibition of ABL tyrosine kinase activity and enhanced } \\
\text { autophagy } \frac{34}{4}\end{array}$ \\
\hline Terazosin & $\begin{array}{l}\text { Activation of PGK1 and HSP90, increased ATP levels, and } \\
\text { reduced } \alpha \text {-synuclein levels } \underline{35}\end{array}$ \\
\hline \multicolumn{2}{|c|}{ Mitochondrial function } \\
\hline $\begin{array}{l}\text { Ursodeoxycholic } \\
\text { acid }\end{array}$ & Restoration of mitochondrial function \\
\hline$N$-acetylcysteine & Antioxidant effect and elevation of glutathione levels $\underline{36}$ \\
\hline Glutathione & $\begin{array}{l}\text { Reduction in reactive oxygen species and free radical } \\
\text { levels }\end{array}$ \\
\hline \multicolumn{2}{|c|}{ Neuroinflammation } \\
\hline Azathioprine & Modulation of peripheral immune system profile \\
\hline $\begin{array}{l}\text { Sargramostim } \\
\text { (G-CSF) }\end{array}$ & Induction of Treg immune responses 37 \\
\hline AZD3241 & $\begin{array}{l}\text { Reduced oxidative stress and neuroinflammation through } \\
\text { inhibition of myeloperoxidase }\end{array}$ \\
\hline
\end{tabular}

\section{Other}

Inosine Elevation of urate levels

Exenatide GLP-1 receptor activation leading to inhibition of apoptosis,

reduced microglial activation and neuroinflammation, reduced oxidative stress, and promotion of neurogenesis

Isradipine Neuroprotection through blockade of L-type calcium channels in substantia nigra 41

Deferiprone Iron chelation

Not started

Safe and tolerable but no clinical benefit in phase II trial

Single-centre randomised placebo-controlled trial currently enrolling patients

Randomised placebo-controlled trial currently recruiting patients

Small open-Iabel phase II study showed no changes in indicators of oxidative damage or brain glutathione levels $\frac{36}{6}$

Double-blind trial completed, with no clinical benefit demonstrated over placebo

Single-centre randomised placebo-controlled trial about to start enrolling patients

Phase I placebo-controlled trial completed Generally well tolerated, with reported modest improvement in UPDRS part III scores $\frac{38}{2}$

Phase 2a randomised placebo-controlled trial completed

Safe and well tolerated with reduced nigrostriatal distribution of microglia 39

Randomised placebo-controlled phase III trial halted early in 2018, with results awaited

Well tolerated, with improvements seen in UPDRS part III

scores in randomised controlled trial 40

Phase III trial currently in set-up

Multicentre phase III trial recently completed, with no improvement in motor or quality of life outcomes

Phase II randomised double-blind placebo-controlled trial completed, demonstrating reduced iron content in caudate and dentate nucleus

No significant clinical benefit $\underline{42}$ 
The other treatments are like

- Targeting non dopaminergic neuro transmitter systems like by using the drugs like Safinamide having multi modal actions \& additionally cholinesterase inhibitors like rivastigmine\& donepezil have been trialled for their ability to reduce falls in PD

- Neurotrophic factors such as glial cell line derived neurotrophic factor [GDNF] have beneficial effects on dopaminergic neurons in pre clinical models and there has been much interest in developing neuroprotective therapies based upon neurotropic factors \& there is a GDNF analog i.e., Neurturin has also been trialled in patients with similar results to those who seen with GDNF namely promising open label trials that have failed to translate to clinical benefit in larger trials \& it has recently been reported in a press release that the agent can be delivered without major side effects, although it is too early to say whether it has therapeutic benefits for patients.

\section{3) Regenerative treatments}

These treatments aim to restore dopaminergic tone in a more targeted and physiological manner than can be achieved with current dopaminergic therapies.

- Several of these approaches are now entering clinical trials

- Gene therapies may be used to increase dopamine levels instriatum through introduction of genes that mediate dopamine synthesis

- 2 gene therapies involving genes encoding these enzymes are currently undergoing clinical trials

- Cell based therapies offer another emerging approach for targeted replacement of dopamine to treat dopamine dependent aspects of PD

\begin{tabular}{|c|c|c|c|c|}
\hline Trial & Country & Cell source & $\begin{array}{l}\text { Number of } \\
\text { patients }\end{array}$ & Status \\
\hline $\begin{array}{l}\text { Center for iPS Cell Research } \\
\text { and Application }\end{array}$ & Japan & Allogenic IPSCs & 7 & Started \\
\hline NYSTEM-PD & USA & ESCs (H9 cell line) & 10 & $\begin{array}{l}\text { Pending decision } \\
\text { from FDA }\end{array}$ \\
\hline Chinese Academy of Sciences & China & ESCs & 50 & Ongoing \\
\hline European STEM-PD trial & $\begin{array}{l}\text { UK and } \\
\text { Sweden }\end{array}$ & ESCs (RC17 cell line) & To be confirmed & In set-up \\
\hline $\begin{array}{l}\text { Fujifilm cellular dynamics } \\
\text { international }\end{array}$ & USA & Autologous iPSCs & To be confirmed & In set-up \\
\hline $\begin{array}{l}\text { Allife Medical Science and } \\
\text { Technology Co., Ltd. }\end{array}$ & China & $\begin{array}{l}\text { Autologous iPS-neural stem } \\
\text { cells }\end{array}$ & 10 & In set-up \\
\hline Aspen Neuroscience & USA & Autologous iPSCs & To be confirmed & In development \\
\hline $\begin{array}{l}\text { International Stem Cell } \\
\text { Corporation }\end{array}$ & Australia & $\begin{array}{l}\text { Parthenogenetic ESC-derived } \\
\text { neural stem cells }\end{array}$ & 12 & Ongoing \\
\hline
\end{tabular}

Abbreviations: ESC, embryonic stem cell; FDA, US Food and Drug Administration; iPSC, induced pluripotent stem cell.

- A tricistroniclentivirus vector is also currently undergoing clinical trials \& this treatment consists of genes encoding AADC,TH,GTP cyclohydrolase 1 which catalyses rate limiting step of tetrahydrobiopterin synthesis - A cofactor required for dopamine \& serotonin synthesis

- There are somanytype of treatments that are in phase 1 clinical trials

There are some Advances developed in DBS like

- The pedunculopontine nucleus has recently been trialled as a new target for DBS particularly for gait problems seen in PD

- Initial trials are reported positive impacts on gait \& postural instability\& more rigorous subsequent trials were less promising

- More recently, stimulation of substantianigrareticularis has shown promising effects on axial symptoms in preliminary studies along with stimulation of basal forebrain with subthalamic nucleus for some of cognitive deficits in PD 
- There is a great interest in adaptive DBSi.e., a system in which stimulation delivered to target is adjusted in response to physiological signals

- This type improves clinical response, limits adverse effects and reduces the requirements for battery charges and the associated cost\& further work is required in identifying \&hoped that such technologies will enhance clinical utility of DBS in future

- Non invasive DBS techniques involving the use ofexternal devices delivering electric fields to deep structures would overcome or circumvent need of neurosurgery \& it's associated risks

\section{REFERENCES}

1. https://www.ncbi.nlm.nih.gov/pmc/articles/PMC7400683/

2. https://pubmed.ncbi.nlm.nih.gov/29862163/\#: :text=Recent\%20findings\%3A\%20Deep\%20brain\% 20stimulation, prominent\%20results\%20relating\%20to\%20rehabilitation.

3. https://link.springer.com/article/10.1007/s40473-018-0154-9\#Sec2.

4. https://www.researchgate.net/publication/324730448_Recent_Trends_in_the_Use_of_Electrical_ Neuromodulation_in_Parkinson's_Disease.

5. https://f1000research.com/articles/9-862.

6. https://www.michaeljfox.org/news/new-drug-fda-approved-parkinsons-time.

7. https://search.usa.gov/search?utf8=\%E2\%9C\%93\&affiliate=fda1\&sort_by=\&query=parkinson $\% 27$ $\mathrm{s}+$ disease+new+treatment.

8. https://www.fda.gov/news-events/press-announcements/fda-approves-new-add-drug-treatepisodes-adults-parkinsons-disease.

9. https://www.fda.gov/news-events/press-announcements/fda-approves-drug-treat-parkinsonsdisease.

10. https://www.fda.gov/drugs/new-drugs-fda-cders-new-molecular-entities-and-new-therapeuticbiological-products/novel-drug-approvals-2020.

11. https://www.accessdata.fda.gov/drugsatfda_docs/label/2017/207145lbl.pdf.

12. https://www.youtube.com/watch?v=7ZFWBZ̈pwyg0.

13. https://www.accessdata.fda.gov/drugsatfda_docs/nda/2018/209184Orig1s000TOC.cfm

14. https://www.accessdata.fda.gov/drugsatfda_docs/label/2018/209184s000lbl.pdf.

15. https://www.fda.gov/media/134493/download.

16. https://www.neurologyindia.com/article.asp?issn $=0028$ 3886 ; year $=2018$; volume $=66$;issue $=7$; spage $=26$; epage $=35$; aulast $=$ Radhakrishnan .

17. https://www.parkinson.org/Understanding-Parkinsons/Statistics. 